\title{
Professional training and research: which resources?
}

\author{
Lucia Guidarelli \\ From 71st Congress of the Italian Society of Pediatrics. Joint National Meeting SIP, SIMGePeD, Study Group \\ on Pediatric Ultrasound, SUP Study Group on Hypertension \\ Rome, Italy. 4-6 June 2015
}

The National Plan of Prevention (PNP 2014-2018) [1], which is the key document for the Italian Public Health, underlines the need to realize for all people an empowerment level able to increase or maintain the health control. At international level, the Ljubljana Charter [2] contains the sanitarian systems commitment to rearrange, in the aim to improve continually the quality, with reference to, in particular, the rate cost /efficacy of the system. The manual for medical practitioners and pediatricians (Ministry of Heath, 2010) [3] acknowledges the seven fields of skills for operators, as defined by the Canadian Patient Safety Institute, the CPSI.

Continuous training for health professionals started as a national program in Italy in 2002; some years later (2007) administrative control had been transferred from the Ministry of Health to the National Agency for Health Services, Agenas. At distance training and online updating are now becoming very common, close to traditional kinds of events for training, always in respect of the Evidence Based Medicine (EBM).

We can identify, in the continuous sanitarian training system, different roles and various kinds of providers. Relevant organisations include the National Committee for Training, in the Ministry of Health, the Warranty Committee, and the National Observatory about Quality of Training.

Regarding research in the field of health, we can consider it as the architrave of the National Health Service; the Report on Health Status in Italy 2012-13 [4] defines some essential aspects of it, such as the improvement of criteria of selection of the projects, to simplify bureaucratic procedures, evaluation and the rapid spread of the results.
The National Committee for Sanitarian Research defines the program and initiatives, monitors and evaluates the results. Research institutes involved in Italy must accept different challenges, according with the Singapore Declaration [5], which defined some criteria about loyalty and professional honesty.

The European Union invested 80M Euro in research with Horizon 2020, in the aim of destroying barriers and realising, all over the world, a common environment concerning knowledge, research and innovation.

A recent piece of research related to the food habits in the age of complementary feeding is Nutrintake 6/36 [6], the first Italian study which confirms some excesses and deficiencies in the diet. It suggests the opportunity of the definition of specific nutritional guidelines.

\section{Published: 30 September 2015}

\section{References}

1. National Plan of Prevention (PNP 2014-2018), Accessed at http://www. salute.gov.it.

2. The Ljubljana Charter on reforming health care, OMS Europe. 1996.

3. Manual for medical practitioners and pediatricians, Ministry of health, Accessed at http://www.salute.gov.it.

4. Report on health status in Italy 2012-13, Accessed at http://www.rssp. salute.gov.it.

5. Singapore Declaration, Accessed at http://singapore statement.org/ statement.html.

6. Zuccotti GV, Cassatella C, Morelli A, Cucugliato MC, Catinello G, del Balzo V, et al: Nutrient intake in Italian infants and toddlers from North and South Italy: the Nutrintake 636 study. Nutrients 2014, 6(8):3169-86.

doi:10.1186/1824-7288-41-S2-A41

Cite this article as: Guidarelli: Professional training and research: which resources? Italian Journal of Pediatrics 2015 41(Suppl 2):A41. 